\title{
La integración de los migrantes en Chile. Asimilación y retórica multiculturalista
}

\section{Integration of Migrants in Chile. Multicultural Assimilation and Rhetoric}

\author{
Leonora Rocío Torres Matus ${ }^{1}$
}

\section{RESUMEN}

En este artículo exploraremos las dificultades y contradicciones en el uso y análisis del concepto de integración de los migrantes internacionales en Chile. A nivel político se utiliza la variante de la asimilación, mientras que desde la retórica se habla de multiculturalismo. Desde las Ciencias Sociales advierten de lo complejo del concepto mismo, por sus implicancias en el uso de conceptos como sinónimos (pluralismo cultural, multiculturalismo, integración) en las políticas públicas y en los proyectos de ley en la materia, que también involucra otras minorías en el país.

Palabras clave: 1. integración, 2. migrantes, 3. élite política, 4. Chile.

\section{ABSTRACT}

In this article we explore the difficulties and misuse of the concept of integration of immigrant into the chilean society, analyzed in the realm of politics and public policy; whereas in the public rhetoric integration is defined using its multiculturalists version, politics defines as assimilation. Social sciences is aware of the difficulty of using this concept in the public policy arena, domestic politics and the new bills regarding immigration. The concept of integration also involves other social and cultural minorities, therefore, makes the use and misuse of the concept more complicated in the political arena. Keywords: 1. integration, 2. immigration, 3. political elite, 4. Chile.

Fecha de recepción: 5 de marzo de 2017

Fecha de aceptación: 31 de marzo de 2017

\footnotetext{
${ }^{1}$ Universidad Pontificia de Comillas, Madrid, Spain.1tmatus@comillas.edu, leonora_t@hotmail.com, https://orcid.org/0000-0002-5449-3117
} 
\begin{tabular}{l|l} 
Integration of Migrants in Chile. Multicultural Assimilation and Rhetoric \\
Torres Matus, L. R.
\end{tabular}

\section{INTRODUCCIÓN. EL ESCENARIO CHILENO EN MATERIA MIGRATORIA Y SUS PROPUESTAS EN POLÍTICAS PÚBLICAS Y PROYECTOS DE LEY MIGRATORIA}

Chile tiene un desfase en cuanto a política migratoria, pues su legislación aún no corresponde a los tiempos actuales (Doña Reveco y Levinson, 2012; Doña Reveco y Mullan, 2014). No cuenta con una institucionalidad pública para la gestión y tratamiento migratorio, ni con una normativa general que regule los organismos públicos que inciden en la materia, ya que no hay un organismo gubernamental o intersectorial que se dedique exclusiva e integralmente a la temática migratoria (Gainza, 2013, p. 167). Las plataformas internacionales han concluido que la reforma a la legislación es urgente y la Organización Internacional del Trabajo (OIT) han elaborado informes en donde destacan que, a pesar de su lentitud, Chile encauza actualmente esfuerzos hacia las reformas necesarias.

El Consejo Nacional de Política Migratoria se concretó desde el Ministerio del Interior y Seguridad Pública durante el segundo gobierno de la presidencia de Michelle Bachelet (2014-2018); busca coordinar a los distintos ministerios en materia de migración al aportar conclusiones y políticas públicas al respecto. Debido a que no cuenta con una institucionalidad específica en materia migratoria, el papel de este consejo es coordinar los programas relacionados entre sí y observar el cumplimiento de las disposiciones presidenciales en materia de derechos. También es importante destacar que toda reforma de tipo legislativa -es decir, la elaboración y presentación de proyectos de ley- proviene del poder ejecutivo, por lo que el parlamento no puede presentar proyectos de ley como tal, sino que en la actualidad y debido a la importancia del tema migratorio en el país, parlamentarios de diversos partidos políticos chilenos presentan mociones al decreto ley actual para mejorar y apoyar las distintas medidas que buscan proteger a los migrantes en sus derechos.

Según el Decreto Ley de Extranjería n 1.094 de 1975 (conocida como Ley de Extranjería y Migración) que rige actualmente al país, es importante entender que tiene un origen marcado por la seguridad nacional y el refuerzo de las fronteras dentro de un momento histórico determinado, de tipo restrictivo (Mármora, 2002, p. 284). Los elementos más importantes de este marco legal son contabilizar las entradas y salidas de extranjeros y los tipos de visados, el cual respondía a este momento histórico específico, cuando se restringió el ingreso de extranjeros casi es su totalidad, por lo que su objetivo era, principalmente, control de fronteras, manejo de los flujos migratorios y otorgamiento de visados de acuerdo al sentido de seguridad nacional. Con respecto al número de extranjeros en el país, los datos del censo de 2017 (Instituto Nacional de Estadísticas [INE], 2018a, 2018b) arrojaron una estimación de 465 mil extranjeros, que representan 2.7 por ciento de la población total del país (17.5 millones). Se estima que la cifra superará las 500 mil personas en el censo abreviado de 2017. 
La relación histórica del país con la migración se caracteriza por su orientación selectiva, basada en la necesidad de poblar ciertos sectores del país y los inicios de una ciencia que se basaba en los estudios de la raza como objeto y concepto científico, hechos que desplazaron a los grupos nativos e indígenas que habitaban los territorios destinados a ser ocupados para faenas productivas y de poblamiento. La intencionalidad en la selección específica de ciertos grupos en beneficio de un desarrollo y poblamiento demográfico muestra una referencia étnica-racial específica en detrimento de la inmigración fronteriza y a favor del poblamiento europeo (Gainza, 2013, p. 169) que imperaba a mediados del siglo XIX. Esta reglamentación dio un giro con la implementación de una política de seguridad nacional con raigambre racista y de selección en el gobierno militar que comenzó en la década de 1970 con el Decreto Ley de Extranjería $n^{\circ} 1.094$ de 1975, el cual no contemplaba el derecho a asentarse permanentemente ni el acceso a beneficios estatales y derechos básicos como la salud, educación, trabajo, vivienda y la regularización administrativa.

Larraín (2010) determina que el centralismo y autoritarismo son los elementos principales de la identidad chilena que permean la política actual y, en su camino a la modernidad, el país busca tener un proyecto común para mantener lo que se construyó durante el período de expansión territorial con la ocupación de la Araucanía durante la segunda mitad del siglo XIX ( de forma intensiva) y el estabilizar las tensiones y conflictos bélicos con los países vecinos, que se suscitaron en el mismo período.

Por tanto, la idea de una unidad nacional basada en esos principios es fundamental para entender el paso hacia la sociedad y política chilenas.

Como argumenta Usallán (2015, p. 9): «Desde un punto de vista de evolución histórica Chile ha asumido y reproducido una imagen de homogeneidad cultural de la comunidad política. Esta se ha construido fundamentalmente desde el poder estatal invisibilizando la diversidad existente mediante la utilización de distintos grados de consenso y violencia».

En 2015 se constituyó el Consejo Nacional de Política Migratoria, donde se reúnen los ministerios que elaborarán políticas públicas en torno a la materia. La dependencia encargada del asunto migratorio en Chile es el Departamento de Extranjería y Migración (DEM), perteneciente al Ministerio del Interior y Seguridad Pública. Entre sus funciones está garantizar el cumplimiento de la legislación de extranjería vigente en el país relativa al ingreso y egreso, residencia definitiva o temporal, expulsiones y regulación de los extranjeros que permanecen en el territorio nacional. En el marco de la Política Nacional Migratoria del Gobierno de Chile, corresponde a la dependencia analizar las solicitudes de residencia temporal, permanente, refugio y nacionalización, así como promover acciones de acogida que incentiven la integración de los inmigrantes, fomentar la modernización institucional, legislativa y de gestión migratoria en Chile y desarrollar e implementar el Instructivo Presidencial de Política Migratoria. Este departamento ha trabajando en el 
4 \begin{tabular}{l|l} 
Integration of Migrants in Chile. Multicultural Assimilation and Rhetoric \\
Torres Matus, L. R.
\end{tabular}

proceso de elaboración y el documento final de un nuevo proyecto de ley con el fin de presentarlo a la Cámara de Diputados, pero el proceso se retrasó y, en la actualidad, todavía no concluye. El documento fue elaborado a través de consultas con organizaciones sociales y otros estamentos, dando origen a un informe donde se rescataban los aspectos y medidas más importantes que debían estar presentes en la nueva legislación e institucionalidad migratoria.

A nivel de políticas públicas, la ley vigente se ha materializado en instructivos presidenciales (Instructivo Presidencial $\mathrm{n}^{\circ} 9$ del año 2008 y el nuevo Instructivo Presidencial $n^{\circ} 5$ del año 2015, ambos bajo la administración del presidente Bachelet) que corresponden a los convenios internacionales de derechos firmados donde, aunque algunos ministerios tienen oficinas piloto enfocadas en la inmigración y servicios sociales, aún no se puede hablar de diagnósticos de su desempeño. En relación a las políticas de integración, el Estado brinda una batería de beneficios a los inmigrantes en situación regular, la cual se sitúa dentro de las políticas para la población en situación de vulnerabilidad que no distinguen entre chilenos y extranjeros, ni por su situación económica. El reconocimiento dentro de un estado de vulnerabilidad ha sido explicado por Thayer Correa (2013) debido a que la población migrante queda encapsulada en una suerte de falso reconocimiento como sujeto vulnerable y demandante de derechos restringidos por su condición de migrante y es reconocida como un sujeto de derechos plenos en pocas instancias.

Martínez, Soffia, Cubides y Bortolotto (2013, p. 182) explican que el tratamiento del tema migratorio en el poder legislativo ha sido escaso y no ha existido ninguna comisión parlamentaria abocada de manera particular al tema. Además, faltan especialistas que empujen medidas a través de iniciativas específicas.

Desde el parlamento chileno, las comisiones que han tocado de manera directa esta temática ha sido las de tipo permanente de la Cámara de Diputados, la comisión de Gobierno Interior, Ciudadanía y Regionalización. Las que han tenido una relación tangencial han sido la comisión de Relaciones Exteriores, Asuntos interparlamentarios e Integración Latinoamericana y la comisión de Derechos Humanos y Pueblos Originarios.

Esta última comisión ha presentado oficios y mociones relacionados a la migración y la necesidad de contar con una nueva legislación acorde a los convenios internacionales suscritos por Chile.

En 2015 se aprobó la resolución $n^{\circ} 388$ «que solicita a la presidenta el envío de un nuevo Proyecto de Ley Marco sobre Migraciones» (Cámara de Diputados de Chile, 2015), en 2016 se envió a la Cámara de Diputados una moción que «Modifica el Decreto Ley n ${ }^{\circ}$ 1.094 de 1975, Ley de Extranjería, y establece normas para favorecer la integración de los migrantes y la migración segura» (Boletín n 10779-06). 
La moción referida a la integración de los migrantes y la migración segura señala en su artículo $1 .^{\circ}$ que:

"Las políticas de integración tendrán por objeto asegurar los derechos y exigir las obligaciones respectivas que poseen los extranjeros titulares de visaciones en el país y facilitar su participación en la comunidad nacional, donde la intensión del migrante en buscar una vida acorde a sus necesidades en otro país - que es el derecho a migrar-, debe armonizarse con las reglas que son propias de las comunidades políticas, las cuales como titulares de sus territorios, son libres y soberanas para regular el ingreso y admisión a su seno. Las normas migratorias son, precisamente, las llamadas a determinar cómo se concilian las determinaciones del arbitrio del migrante, para elegir el lugar donde vivir, con las de la comunidad a la que estos aspiran a integrarse. Siendo la migración un asunto complejo y que nunca terminará de discutirse y explorarse en su totalidad en el debate político, la legislación debe revisarse periódicamente para encausar sus flujos mediante incentivos y desincentivos, así como para orientarla al mejor beneficio del país de que se trate" (Boletín n 10779-06 del 23 de junio, 2016, p. 2).

Por tanto, la forma en que se entiende la integración de los migrantes estaría supeditada a la ley, institucionalidad, procedimientos legales, valores, tradición y formas culturales, sociales y políticas ya existentes en el país, pero observando y protegiendo los derechos. Más adelante habla de que los migrantes deben participar en la toma de las decisiones que les competen y que el Ministerio de Educación debe incluir contenidos mínimos obligatorios las temáticas de migración y multiculturalismo.

Usallán (2015) argumenta que el asimilacionismo es la medida que se ha utilizado desde la gestión política en Chile porque,

"La hegemonía de un paradigma como el asimilacionista aún pervive en el contexto político y normativo chileno. Si bien no podría decirse que existen políticas abiertamente excluyentes, lo cierto es que la ausencia de políticas proactivas, que abran el camino al pluralismo cultural es notoria. Suele ser una práctica habitual el hecho de que las instituciones asuman una retórica discursiva progresista afín a los postulados del pluralismo cultural, pero que en la práctica no se produzca una modulación de la gestión de la migración acorde a tales postulados. A pesar de lo mucho que se ha avanzado en el ámbito académico y en la propia sociedad civil, donde la cuestión de la gestión democrática de la diversidad llegó para quedarse, la voluntad política para lograr un proyecto de comunidad política inclusiva es insuficiente" (Usallán, 2015, p. 14).

"En este sentido, en el caso chileno no encontramos elementos de coherencia entre las políticas actuales de gestión de la diversidad y el paradigma del pluralismo cultural. Podríamos hablar de la prevalencia de un paradigma asimilacionista en transición." (ídem) 
$6 \begin{aligned} & \text { Integration of Migrants in Chile. Multicultural Assimilation and Rhetoric } \\ & \text { Torres Matus, L. R. }\end{aligned}$

Al evaluar dicho proyecto de ley -que debió haberse presentado en 2017-, es importante preguntarse si busca una migración orientada hacia las necesidades de desarrollo y establece políticas para la búsqueda de trabajadores calificados para ciertas áreas económicas (llamadas políticas de flujo de contingentes de trabajadores en algunos países, dentro de la argumentación teórica neoclásica), o si se fomentará una migración basada en los derechos y la reunificación familiar. Ambas posturas no son excluyentes entre sí, pero si se apuesta por la primera, las políticas públicas deberán ajustarse a una noción de asentamiento transitorio o permanente. Alemania y Estados Unidos ya han abordado el asunto por medio de sus programas de trabajadores invitados, donde no hubo mayores esfuerzos en la integración debido a que se pretendía que fueran de corta estadía. Sin embargo, cuando resultó evidente que los migrantes se establecían permanentemente, hubo que cambiar la respuesta hacia medidas de incorporación del migrante en términos educativos, de salud, vivienda, derechos sociales, políticos, uniones y matrimonios entre nacionales y extranjeros, el papel de las organizaciones migrantes en la toma de decisiones, emprendimientos laborales y apoyo al autoempleo, entre otros, situación que tendrá que enfrentar Chile en el corto plazo debido a las exigencias actuales. En cualquiera de los casos, la institucionalidad presente y el marco legal ya no son suficientes, por lo que se debe legislar acorde a los escenarios futuros, donde el asentamiento permanente será la norma y el Estado debe estar preparado para enfrentar esos hechos.

Para 2018 y con la coalición de centro-derecha en la presidencia (segundo mandato del presidente Sebastián Piñera, en curso), se envió un nuevo proyecto de ley que, en términos simples, es el mismo presentado en su primer gobierno (2013-2017) con indicaciones sustitutivas, tomando en cuenta varios aspectos del proyecto del mandato de Michelle Bachelet, como la creación de un Servicio Nacional de Migración, por ejemplo. El proyecto fue aprobado en su primer trámite constitucional en octubre del 2018, por lo que tiene muchas posibilidades de que se convierta en ley en poco tiempo.

Valenzuela (2014, p. 28) argumenta que la lentitud en las reformas y cambios legislativos importantes se debe al bajo número de extranjeros en el país, la falta de un cambio constitucional y, por otro lado, al índice de desempleo que -a pesar del crecimiento económico de Chile- se mantuvo en niveles medios-altos (cerca de 10\%) durante los períodos 2000-2007 y 2009-2010. Con dicho índice, cualquier política de plena apertura a los inmigrantes se vuelve impopular entre la opinión pública y los políticos se resisten a cambios de gran amplitud que puedan tener consecuencias de tipo político-electoral. La inmigración y la fuerza de trabajo, por tanto, se autoregula con los ciclos económicos y los contextos económicos y laborales vigentes. En la actualidad, la estructura legal se mantiene estancada y la estructura administrativa que gestiona la migración está supeditada aún bajo la lógica de la seguridad nacional, pero con una suerte de tolerancia al ingreso y la 
posibilidad de cambiar el estatus legal-administrativo a una residencia permanente (Gainza, 2013, p. 180) dentro de las llamadas políticas de acceso.

Otros autores, como Macarena Machín (2011), relacionan el modelo de desigualdad socioeconómica existente en Chile con un patrón discriminatorio hacia el trabajador inmigrante, la cual es la estructura laboral presente en Chile (informal, pocos derechos y garantías laborales) y donde los migrantes se insertan en los estratos más vulnerables (Portes y Rumbaut, 1990).

Los medios de comunicación han propiciado la sensación de amenaza (Rosenbluth, Littin, Farfán y Rubio, 2012) de los contingentes de trabajadores extranjeros que llegan al país, lo que puede ocasionar una mayor precarización de las condiciones laborales para los locales porque los extranjeros realizan sus labores por menores ingresos y sin beneficios, además del sensacionalismo discriminador que estigmatiza a ciertos grupos de migrantes quienes, en muchos casos, son los que se encuentran en edad laboral (Navarrete, 2017); por tanto, el estigma negativo de la inmigración es un factor importante a considerar al momento de estudiar el fenómeno migratorio y la respuesta de las élites políticas.

Se argumenta que, debido al bajo número total de la inmigración internacional y a que la mayoría de esta población provienen de Latinoamérica, las políticas de integración no son tan urgentes porque se considera que la cercanía cultural e idiomática con Chile les permitiría incorporarse de forma rápida si cuentan, en su mayoría, con un nivel socioeducativo incluso mayor que los nacionales, por lo que se esperaba una forma de integración exitosa. Sin embargo, es evidente que esto no se cumplirá en muchos sentidos y se necesitan políticas específicas en torno a la diversidad cultural que implica la inmigración internacional, especialmente en las áreas de la educación, salud, vivienda, entre otras. La cercanía cultural e idiomática no son elementos constitutivos del éxito en la incorporación a un nuevo medio.

\section{EL DISCURSO HACIA LA MIGRACIÓN INTERNACIONAL DESDE LA ÉLITE POLÍTICA}

El papel de la élite política, los conglomerados de partidos políticos en Chile sobre la migración (Torres, 2017) y las voces minoritarias se puede caracterizar por un acuerdo transversal hacia el respeto a los derechos humanos y a la no discriminación como base estructural de referencia, se observan ciertas diferencias en el tipo de política migratoria que incluye tanto una nueva legislación como a la institucionalidad y políticas públicasdonde se apuesta por una migración selectiva en relación a la realidad económica y laboral del país.

Se descarta la propuesta de apertura a contingentes de trabajadores calificados, mientras que, en el otro espectro, se apela hacia una migración basada en los derechos y en 
la reunificación familiar, sin mediar un trasfondo específico en torno al posible aporte que pueden brindar al país los nuevos extranjeros, el cual podría ser amplio y positivo.

Estas dos posturas no son contrapuestas pero, desde el punto de vista político, cualquier tipo de adhesión a una u otra tiene consecuencias y al revisar la literatura internacional resulta evidente el papel de los partidos políticos en el tema migratorio ha tenido resultados variados, dependiendo de las condiciones económicas, la relación del congreso con la presidencia y los grupos de poder, el lobby de los grupos migrantes y de derechos humanos y el poder de voto de las minorías en la elección de alcalde, congresista, entre otros cargos públicos (Organisation for Economic Cooperation and Development [OECD], 2010).

La reforma de la ley migratoria en Chile se ha visibilizado considerablemente antes de las elecciones presidenciales del año 2017 (Romero, 2016), pero esta urgencia en reformas legislativas cuenta con una data mayor, tanto en las mociones e intervenciones de distintos políticos en las sesiones del congreso como en otras instancias, sin embargo, al observar de forma específica el papel de la migración en el debate político puede afirmarse que es menor, comparado con otros temas de la agenda política.

Tampoco existen datos de la composición de los partidos políticos ni del apoyo a figuras políticas de origen extranjero o de otra minoría de forma explícita, cuando en otros países son ampliamente estudiados dentro de la literatura especializada en migración. Al contar con voces diversas y figuras políticas de origen extranjero, posiblemente exista un mayor interés del partido o conglomerado de apuntar hacia reformas en la materia, a diferencia de coaliciones y partidos que no tienen dicha diversidad.

Los partidos son los ejecutores políticos más importantes en las democracias modernas, por lo que la integración política de los grupos migrantes no depende solamente de la eliminación de políticas discriminatorias e implementación de reformas en las políticas públicas, sino de las actitudes de los partidos políticos (Aleinikoff y Klusmeyer, 2002, p. 58). El incremento de la representación de las minorías étnicas en el parlamento y poder ejecutivo depende de los partidos políticos y su capacidad para apoyar a candidatos que tienen un origen migrante, por lo que la injerencia de los partidos es clave, por ejemplo, en su actitud hacia la discriminación y la xenofobia. Los autores han visto que, en algunos casos, los partidos de centro han tomado la carta antiinmigración para ganar votos que podrían haber sido de los partidos más del espectro centro-derecha (Aleinikoff y Klusmeyer, 2002, p. 60).

Cuando las divisiones de izquierda/derecha pueden parecer irrelevantes en el tema migratorio, es necesario explicar por qué las políticas de las últimas décadas han sido más flexibles de lo esperado (OECD, 2010, p. 139), lo que indica que el beneficiario de la inmigración se concentra en pocos actores sociales organizados, mientras que el costo de la 
migración se distribuye en un número mayor de individuos, con un grupo dividido como oponente.

Algunos estudios muestran el desacuerdo de la opinión pública con respecto a las políticas públicas; en otros estudios, el papel de los medios de comunicación ayudan a moldear imágenes e intentan ser coherentes con imágenes colectivas -que pueden ser negativas, al estar basadas en prejuicios.

Todo esto puede alcanzar las bases políticas y las respuestas son diversas: como argumenta Boswell (2008) en su análisis de la política británica y alemana en torno al tema de la migración laboral durante 2004 y 2006, las respuestas han sido de tipo tecnocráticas - dar respuesta a un problema- o democráticas -basadas en una reflexión mayor que explora las consecuencias y el valor mismo del multiculturalismo-. El papel de los grupos de expertos y la información de corte científica ha moldeado estos dos tipos de justificación y, por lo tanto, hay serias dudas y escepticismo en torno a la imparcialidad de la información y se cuestiona si existe algún tipo de maniobra política o del empresariado para apostar por medidas tecnocráticas que favorezcan la llegada de mano de obra extranjera.

Cristina Boswell (2008, p. 9) explica que esta divergencia tiene tres posibles causas: la dinámica parlamentaria, el clivaje ideológico de los partidos y los patrones establecidos en el debate en torno a la migración. Con respecto al clivaje ideológico, en el caso analizado los países gobernados por partidos de centro-izquierda han llegado a una respuesta de tercera vía en estas reformas (Boswell, 2008, p. 9), enfatizando el impacto de la globalización y la importancia de atraer trabajadores calificados para una economía basada en el conocimiento. Esto ha provocado algunas respuestas ambivalentes por parte de partidos proteccionistas, tales como los Demócratas Cristianos en Alemania.

Por otro lado, los conservadores ingleses se han opuesto al recurso étnico o cultural, mientras se consideran a sí mismos como pro-negocios y un partido relativamente neoliberal, abierto al nuevo talento que pueda reactivar la economía. Su postura es bastante compleja porque no está enfocada en una agenda pro-modernizante, sino a una de tipo valórica que se aleja mucho de la base del conocimiento de los expertos de tipo tecnocrático.

Por tanto, dentro de los partidos, tanto la visión basada en los expertos como la apuesta ideológica, de valores y contenido social se enfrentan al momento de las elecciones con el objetivo de mantener las bases votantes tradicionales de sus partidos, pero los argumentos comienzan a dirigirse hacia las de orden económica cuando llegan al poder.

Finalmente, Alemania tiene un recuerdo colectivo cercano al fracaso de la política de los trabajadores invitados, por lo que todo tipo de reformas y políticas públicas posiblemente relacionadas tienen un rechazo social. 
A diferencia del caso anterior, Inglaterra no experimentó este proceso. El estudio de Emma Hill (2016) sobre los discursos políticos de la coalición conservadora/demócrata que se mantiene en el poder desde 2010 en el Reino Unido, concluye que se unen dos elementos importantes en el discurso político acerca de la inmigración: la hospitalidad y la identidad nacional y estatal. Lo interesante es que los discursos combinan estos dos elementos tanto de forma complementaria como antagonista, lo que podría derivar en un discurso anti-inmigratorio capitalizado desde los aspectos negativos (uso del sistema de bienestar de los migrantes, etcétera) y que pude tornarse hostil de forma rápida.

En el caso irlandés, Haynes y Devereux (2016, p. 213) señalan que a partir de la recesión económica de 2008, los políticos de todos los sectores perpetuaron la imagen del inmigrante como una amenaza, a pesar de que la izquierda apoya los derechos de los migrantes, todos los actores políticos han contribuido a mantener la noción de que son una carga a la economía e incluso, personas fraudulentas, equiparable a la delincuencia local.

Lo relevante de su análisis es el declive de la inmigración desde países de la Unión Europea (UE) por lo que, en general, la inmigración no ha aumentado tanto como para fundamentar el discurso de la carga inmigratoria; sin embargo, los políticos no le mencionaron este dato a la ciudadanía irlandesa. Además, el tema migratorio tiene poca visibilidad en los debates, lo que provoca que los inmigrantes de bajos recursos sean los más afectados.

En general, Haynes y Devereux señalan que no hay una agenda pro-inmigración, sino que ciertos políticos que intentan defender los derechos de los inmigrantes sólo se enfocan en refutar el discurso anti-inmigratorio de ciertos grupos y no hay una agenda a largo plazo o discusión profunda acerca del tema.

Finalmente, los autores indican que hay desinformación y confusión por parte de la opinión pública en torno a la inmigración (Haynes y Devereux, 2016, p. 211) y, por ello, los líderes políticos deben basar sus discursos en datos objetivos ( de tipo cuantitativa) y no en discursos que no provienen de los hechos para que la ciudadanía pueda llegar a conclusiones informadas.

Por último, Breunig y Luedtke (2008) confirman que la conclusión de la política inmigratoria en partidos con preferencia hacia la inmigración es independiente de la división derecha/izquierda.

Sugieren que el espacio entre la opinión pública -mayormente anti-inmigración- y la posición adoptada actualmente por los partidos políticos puede ser explicada por la fuerza del control institucional sobre la percepción de la mayoría de los ciudadanos de la inmigración, que funciona como factor que determina el apoyo dado por los políticos antiinmigración. 
En consecuencia, este tipo de opiniones obtienen peso sobre las preferencias de los partidos políticos para orientarse hacia la restricción migratoria y el endurecimiento de las medidas de adopción de ciudadanía, como se aprecia en los casos analizados de países de la OECD.

Otro elemento importante es la llegada a la discusión política de grupos de profesionales de manejo de riesgo, ya que el riesgo es una de las consecuencias de la globalización, donde la migración toma relevancia como uno de los temas en agenda que, en muchos casos, tiende a criminalizarse porque pone en riesgo la soberanía y la seguridad (Bigo, 2006). Estos asesores pueden tener una gran influencia en los círculos de poder del mundo parlamentario y la presidencia, por lo que es un aspecto importante a destacar en el estudio de los procesos legislativos en materia migratoria.

El concepto del multiculturalismo que manejan los partidos y élite política es solamente un recuento de la diversidad cultural del país -especialmente en lo referido a la base étnica indígena- (Barabas, 2014) y no se refleja en planes ni programas específicos que protejan o ayuden a mantener esta diversidad.

Tampoco la incluyen en sus planteamientos ni proponen representantes con orígenes diversos debido a que el sistema de partidos es cerrado y tradicional, lo que no permite la entrada de nuevas voces y propicia esta base monocultural y centralista (Pairican, 2014, p. 365), un asunto clave para entender la identidad del país como sociedad cultural homogénea: la diversidad es un hecho constatable, pero no ingresa a las cúpulas de poder ni manejo político en la medida adecuada.

Lo anterior también se refleja en la poca visibilización de las identidades regionalistas (Pairican, 2014, p. 365), y en que algunos partidos han intentado ingresar a la política bajo el argumento de incluir las dinámicas e identidades que no se reflejan en esta base homogénea replicada en el congreso.

Sin embargo, durante 2015 y 2016 surgió la posibilidad de que esto cambie debido a diferentes proyectos de ley propuestos que conllevan un cambio en esta estructura rígida, como es el caso de las cuotas de género y la medida impulsada por la presidenta Bachelet de tener representación constitucional indígena en la constitución y el parlamento. No obstante, es importante señalar que medidas aún no se concretan en proyectos de ley ni modificaciones a las leyes actuales. 
\begin{tabular}{l|l}
12 & $\begin{array}{l}\text { Integration of Migrants in Chile. Multicultural Assimilation and Rhetoric } \\
\text { Torres Matus, L. R. }\end{array}$
\end{tabular}

\section{EL CONCEPTO DE INTEGRACIÓN DE LOS MIGRANTES. LA APROXIMACIÓN ACADÉMICA AL CONCEPTO Y TIPO POLÍTICA CON DISTINTOS RESULTADOS Y RESPUESTAS CONTRADICTORIAS.}

A pesar de los esfuerzos para materializar una política migratoria basada en una ley con más de 30 años de antigüedad y con muy pocas reformas en relación al tema migratorio, el estudio de la Universidad Diego Portales sobre representación de las élites parlamentarias y la ciudadanía (Castillo, 2011), señala una brecha con respecto al tema migratorio: la inmigración (en general) es el tema que genera más distanciamiento entre élite y ciudadanía. La emigración es apenas percibida.

Los ciudadanos, particularmente los más pobres, ven a los extranjeros como una amenaza para sus fuentes laborales (Castillo, 2011, p. 29). Navarrete (2017, p. 202), por el contrario, ve una diferencia entre una opinión pública abierta a la discusión -y modelos de tipo norteamericano de tipo multicultural- y las apreciaciones de la clase parlamentaria, encargada de generar políticas sobre el papel de la inmigración y su deseabilidad.

En relación a la integración de los migrantes, Chile no tiene una política explícita al respecto, lo que indica que son un colectivo sin derechos plenos, como ocurre en muchos países, incluso con políticas explícitas pro-integración (Foro Bicentenario, 2008, p. 118).

La legislación chilena actúa reaccionando a los fenómenos migratorios (Gainza, 2013; Doña Reveco y Mullan, 2014) y el modelo de integración en la gestión migratoria (Usallán, 2015) -a través de modelos de gestión con distintos grados de elaboración, bajo el amparo de un Estado- nación determinado, una definición de democracia y un sistema político de tipo republicano- presente en Chile refleja un contexto donde hay políticas públicas para la integración de los refugiados, pero ninguna dirigida explícitamente hacia los inmigrantes (Jiménez, 2011).

Chile ha intentado adscribirse a la tendencia de las fórmulas multiculturales como Estado, pero esto no tiene sustento ni institucionalidad porque no existe con una normativa general. Charles Taylor (1994) demuestra en su libro de Multiculturalismo. Examinando las políticas de reconocimiento que es posible sobrellevar la tensión generada entre una promoción de tipo pública de las diferencias culturales, sobre la base del respeto a los derechos humanos, lo cual funciona como una base de igualdad aplicada en varios países democráticos donde impera el discurso multiculturalista. En la práctica, esta base promueve cierto tipo de medidas basadas en la defensa de los derechos humanos y la no discriminación.

Las demandas de reconocimiento de los grupos poco representados en las esferas de poder y cómo se articula este tipo de demanda en los Estados democráticos son unos de los principales aportes de este planteamiento. Esto da paso a la reacción de los Estados, la cual nunca es neutral, pues tiende a preservar un sustrato cultural por sobre otro y la toma de una postura en esta materia es un elemento fundamental de análisis porque involucra tanto 
la política como la noción de sustrato social e histórico que, -en muchos casos,- se basa en lineamientos provenientes de las élites.

El concepto mismo de la integración, como un proceso donde los inmigrantes se transforman en nuevos miembros de la sociedad receptora, ha sido descrito varias veces como asimilación, integración o inserción (Joppke y Morawska, 2003; Bauböck et al., 1996; Bauböck, 2005). Ninguno de estos sinónimos es meramente descriptivo ni autoexplicativo, ya que tienen una carga de significados mediatizada por su contexto, así como connotaciones normativas que describen los distintos tipos de carga simbólica en el proceso de adaptación, tanto desde la sociedad receptora como de parte de los inmigrantes.

Cada versión del concepto puede ser usado de diferentes formas (Joppke y Morawska, 2003; Bauböck et al., 1996, p. 9; Favel, 2014). Por ello, la forma en que se definen los conceptos, su utilización, la carga normativa, cultural o social que tienen en cada contexto y sus consecuencias en la elaboración de nuevos marcos legislativos y políticas públicas en torno a la migración internacional, son elementos fundamentales.

Al emplearlos como sinónimos (asimilación, integración o inserción) no fomentan una comprensión real de los mismos y sus resultados potenciales difieren de los resultados de las políticas públicas basadas en ellas.

Favel (2014) señala que el concepto de multiculturalismo en relación a la inmigración ha tomado un nuevo aire debido a la preocupación por el distanciamiento latente entre las posiciones sobre el tema. Para el autor, la versión asimilacionista de la integración (Brubaker, 2001) predomina en los estudios como condición crucial de éxito de los nuevos inmigrantes en la sociedad estadounidense por su adherencia hacia la visión funcionalista de la misma.

En Estados Unidos el concepto de asimilación se sigue caracterizando desde la visión unilineal -donde la sociedad de clase media blanca es el referente-, pero en la Unión Europea la integración es el concepto popular en la política y retórica, especialmente en Francia.

Generalmente, en los debates políticos se hace referencia a un punto medio entre el conformismo hacia las normas y los valores del país de acogida, con una mirada de temor hacia el separatismo, el cual lleva a una sobrerrepresentación de los valores europeos. Alude a una acomodación mutua y bidireccional entre la sociedad de acogida y el inmigrante, pero es Pseudo-positiva y post-factual porque no ofrece criterios claros que permitan operacionalizar y medir a este último.

Al considerar esta dicotomía, el concepto de integración como una necesidad se torna aceptable, ya que la posibilidad de un desastre que termine en disolución no tiene cabida. Por tanto, el concepto en sí reafirma el aspecto positivo de unión -a la fuerza, si se deseahacia una cohesión necesaria e indiscutible, donde la re-imaginación de la unidad social, cohesión y unidad Estado-céntrica se generan fuera del escenario de la llegada de la diversidad y los conflictos (Favel, 2014, p. 168-169). 
En suma, el concepto de integración es difuso (Honohan, 2016, p. 252), y aunque inicialmente se relacionaba con lo económico, social y político, ahora el interés en la igualdad de las oportunidades económicas y los deberes de los migrantes se ha enfocado en los problemas de la diversidad de sus orígenes, el concepto de multiculturalismo se ha orientado hacia la retórica política (Honohan, 2016; Hampshire, 2013), pero no se han revisado estas políticas, ni cuestionado sus resultados.

Lo que predomina en la actualidad son los requisitos desde origen -previos al proceso mismo de migración- y las pruebas de compatibilidad cultural y lingüística, así como la integración cívico-política; es decir, las posibilidades objetivables de un individuo y grupo familiar de poder incorporarse de forma rápida al medio se ponen a prueba según sus potenciales cercanías cultural, social, laboral y valórica.

Para Honohan (2016), la integración cívica -vista como la última etapa de una integración exitosa - no es la cara aceptable de la asimilación porque está mediatizada por requisitos culturales estándares que no necesariamente son exigidos a la comunidad de un país de la misma manera, ya que se asumen que comparten y aprueban estos requisitos, lo que en muchos casos no ocurre de esta manera (subculturas, grupos contraculturales, etc.)

Siguiendo este argumento, Hampshire señala que los Estados democráticos no son neutrales y promueven un perfil cultural liberal que termina imponiéndose en diferentes programas, tanto hacia migrantes como otras minorías.

En el caso europeo (especialmente en los países de la Unión Europea), la brecha entre el discurso y la práctica se ve reflejada en los programas de integración, donde los principios universalistas excluyen de facto todo tipo de principios que no estén alineados con esta base unificadora; si el discurso apela a la base de la igualdad y la no discriminación, por ejemplo, en los programas de integración y procesos de acomodación que realizan los Estados se espera que los migrantes ajusten sus creencias y sus comportamientos a modelos específicos de asimilación que no necesariamente coinciden con el discurso, especialmente en el área religiosa (Hampshire, 2013, p. 154).

Chile se define como un país pluricultural y pluriétnico en términos de su diversidad lingüística y étnica (Gómez, 2003, p. 126), en especial a lo referido al sustrato étnico e indígena fundacional, donde los partidos políticos -en general-apelan hacia la defensa de los derechos humanos, no discriminación, equidad e inclusión, pero el planteamiento del tema migratorio aún es insignificante en las propuestas y declaraciones de principios de los partidos (Torres, 2017).

Esta retórica multicultural predomina en las propuestas políticas de los partidos, pero en la práctica defiende ciertos tipos de valores (republicano, laico, occidental, monolingüístico), que no incluyen las distintas manifestaciones culturales de forma explícita en la política de alto nivel, por ejemplo, la representatividad de las diferencias culturales en el parlamento y gobierno, además de otras posibles formas de ordenamiento y creación política, fuera de la lógica de partidos y representación parlamentaria. 
Los partidos que tienden a verse como defensores de cierto sustrato tradicional podrían tener dificultades en la lectura real de los problemas y necesidades de grupos con una base cultural distinta, lo cual no significa que sea un aspecto negativo, ya que los partidos son una estructura que tiene como misión representar ciertos valores y posturas de forma clara y así atraer nuevos simpatizantes, sino que aquello que pudiera parecer una dificultad en realidad es una retórica que tal vez no concuerde con sus principios y defensa de un cierto núcleo puede alejarlos de la ciudadanía.

La diferencia cultural, por tanto, se invisibiliza bajo los preceptos de una sociedad republicana para, como Estado, seguir los pasos necesarios hacia la modernidad económica y de clase política y salir del colonialismo, camino que tomaron muchos países latinoamericanos (Larraín, 2001; Donoso Rojas, 2006). Castles (2000) caracteriza la asimilación como "la política de incorporar a los migrantes a una sociedad a través de un proceso unilateral de adaptación" (2000, p. 137).

Es decir, se espera que los inmigrantes dejen sus aspectos distintivos de tipo lingüístico, cultural y social para convertirse en sujetos indistinguibles de la población mayoritaria, integrándose como ciudadanos. El modelo republicano, por lo tanto, facilita el acceso a la ciudadanía de las segundas y terceras generaciones originarias de contingentes extranjeros, lo que supondría, finalmente, el goce de derechos plenos. Es un modelo meramente individual, basado en la igualdad, pero que también asume que los aspectos de comportamiento social, político, cultural y secularismo se suman a las virtudes del civismo republicano y esta contradicción no deja espacio a la diversidad cultural ni a la formación de comunidades étnicas, es por esto que hay dos factores que niegan el modelo republicano: la marginalización y el racismo. Estos dos elementos, tanto en su frecuencia como en su presencia, permiten observar que este modelo no funciona y ha propiciado la politización de la situación de las minorías en continuos debates sobre inmigración y legislación en torno a la nacionalidad.

La respuesta al modelo republicano asimilacionista ha sido el pluralismo; Castles (2000, p. 138-139) explica que éste implica que los inmigrantes tienen garantizada su igualdad de derechos en todas las esferas de la sociedad, sin esperar que dejen de lado su diversidad, aunque usualmente hay una expectativa de conformidad con ciertos valores clave. En este caso, la membresía en la sociedad civil, proceso iniciado a través de un permiso para inmigrar, lleva a una participación plena en el Estado nación. Este modelo se encuentra en los países clásicos de inmigración como Australia, Estados Unidos y Canadá, donde se apela a que los inmigrantes de larga estadía y con residencia permanente deberían tener acceso a la ciudadanía y nacionalidad plena, en conjunto con la reunificación familiar y el acceso a derechos cívico-políticos.

Este proceso refuerza la idea de la presión de las políticas pluralistas; cuando los migrantes votan, los grupos étnicos ganan poder político. A pesar de lo expuesto, estos modelos no son nuevos porque son una respuesta a la presión ejercida debido a que los modelos asimilacionistas de la década de 1960 -donde se aplicaba un criterio de selección 
racial- fracasaron. En la actualidad la selección sigue teniendo como base criterios de vulnerabilidad económica y humanitaria (en el caso de los solicitantes de asilo y refugio).

El pluralismo cultural, por tanto, presenta dos variantes: la aproximación laissezfaire, la respuesta típica en Estados Unidos, donde la diferencia es tolerada, pero no es un aspecto que el Estado deba proteger ni preservar. La segunda variante son políticas explícitas de tipo multicultural, donde la población mayoritaria acepta la diferencia cultural y hay una trabajo de adaptación de la identidad nacional y las estructuras institucionales. Es decir, elementos como dependencias específicas en la materia con profesionales especializados, la traducción a otros idiomas y el manejo bilingüe dentro del trabajo burocrático, políticas orientadas hacia la preservación cultural de las minorías, concursos públicos para financiar estos programas, apoyo directo a organizaciones de migrantes y minorías, cupos en el parlamento y en partidos políticos, entre otros.

Esto es observable, por ejemplo, en el caso de políticas educativas de países como Suecia, Canadá y Australia. El factor crucial es el Estado de bienestar, en el que el pluralismo cultural necesita combinar políticas públicas que aseguren el acceso a derechos básicos para todos, lo que incrementa las posibilidades de tener una sociedad pacífica.

Bajo esa mirada, Chile ha realizado varios esfuerzos para incorporar los distintos sustratos étnicos y culturales que se encuentran presentes en ciertas regiones del país a la institucionalidad, pero, a nivel de políticas estatales, aún se mantiene el refuerzo de la base monocultural y tradicional que se destacó anteriormente.

Joppke y Morawska (2003, p. 2) señalan que el concepto de integración es uno que posiblemente no exista más allá del análisis académico y que esto se deduce por dos hechos importantes: la adaptación y el uso de los recursos de las sociedades de acogida y el reforzamiento de los lazos transnacionales de los migrantes. Castles (2004) toma en cuenta estas dos tendencias - la resiliencia de la ciudadanía y la disminución de las políticas multiculturales- en conjunto con las medidas asimilatorias y el transnacionalismo son la tónica actual para argumentar que las democracias actuales.

Tanto la inmigración como la noción de democracia, presentan varios dilemas importantes: el de la inclusión formal a la ciudadanía de los inmigrantes, la ciudadanía substancial -que se refiere a los derechos y obligaciones al ser miembro de una comunidad política-, el reconocimiento de los derechos culturales - donde la individualidad no es tan importante como la estructura comunitaria que construyen los inmigrantes cuando el Estado nunca es un ente neutral- y la apropiación de las instituciones políticas con dificultades para manejar las diferencias colectivas porque mujeres, grupos indígenas e inmigrantes forman parte de una estructura que protege la igualdad en la identidad política y ha profundizado la marginación de los grupos políticos sub-representados y excluidos de los centros de poder.

Castles habla de una ciudadanía diferenciada (2000, p. 142) donde la democracia no sólo debe promover la ciudadanía plena y oficial, sino también otro tipo de mecanismos de participación para los grupos usualmente excluidos de los procesos de toma de decisiones. 
El problema de las políticas de universalización de los derechos, donde se enfatiza la dignidad igualitaria a través de derechos y las políticas de la diferencia-que tienen como base el reconocimiento de la identidad única de los individuos y grupos- es parte de las contradicciones de la aproximación multiculturalista en la actualidad. Esto provoca que a nivel local se observan programas que apuntan hacia un intercambio cultural y el respeto a las diferencias, pero el conflicto radica en el traslado hacia los centros de poder político, que no los incorpora.

\section{CONCLUSIONES}

El papel de la migración internacional y la necesidad urgente de reformas legislativas en la materia son factores prioritarios entre las élites políticas, con distintos resultados. En general, existe apoyo directo hacia la creación de una reforma en torno a los derechos y a la no discriminación, pero hay algunas diferencias en lo referente al tipo de política migratoria.

Si se discute una política orientada hacia las necesidades económicas chilenas, donde exista una apertura hacia la atracción de ciertos contingentes profesionales o si el enfoque principal es hacia los derechos de los migrantes y la reunificación familiar, puede afirmarse que no son miradas en conflicto, pero adherirse a una sobre por otra de forma explícita tiene consecuencias en la opinión pública, como se ha venido observado en otros países que han enfrentado esa decisión.

Otro factor que tiene consecuencias es la forma en que un país se enfrenta al asentamiento (transitorio o permanente) de los migrantes. Si la integración se define como asimilación, implica cierto tipos de acciones y discursos que tienen como objetivo mantener un orden previo, reafirmar que la migración no es una amenaza y que las instituciones protegen a todos, sin distinción.

En Chile el debate sobre la integración y sus distintas variantes coincide con una opinión orientada hacia la incorporación del migrante en una institucionalidad precaria con una discusión política reciente, una opinión pública que se ha movido entre actitudes reaccionarias a una visión comprensiva del fenómeno y con una discusión académica en formación y escéptica hacia la retórica multiculturalista de la élite política e institucional.

\section{REFERENCIAS}

Aleinikoff, A. y Klusmeyer, D. (2002). Citizenship Policies for an Age of Migration. Washington, D. C.: Carnegie Endowment for International Peace/Migration Policy Institute. 
Barabas, A. (2014). Multiculturalismo, pluralismo cultural y interculturalidad en el contexto de América Latina: la presencia de los pueblos originarios. Configurações, Revista de Sociología, 14, 11-24.

Bauböck, R. (2005). ¿Adiós al multiculturalismo? Valores e identidades compartidos en las sociedades de inmigración. Revista de Occidente, 264, 45-61.

Bauböck, R., Heller, A. y Zolberg, A. R. (Eds.). (1996). The Challenge of Diversity. Integration and Pluralism in Societies of Immigration (volumen 21). United Kingdom: European Centre Vienna/Avebury Publishers.

Berry, J. W. (1997). Immigration, Acculturation and Adaptation. Applied Psychology, 46, $5-68$.

Bigo, D. (2006). Globalized (in)security: the Field and the Ban-opticon. En D. Bigo y A. Tsoukala. (Eds.). Illegal practices of liberal regimes: the (in)security game. France: Centre d' Etudes Sur Les Conflicts/Librerie L' Harmattan.

Breunig, C. y Luedtke, A. (2008). What Motivates the Gatekeepers? Explaining Governing Party Preference on Immigration. Governance, 21(1), 123-146.

Boletín $\mathrm{n}^{\circ}$ 10779-06. Modifica el Decreto Ley $\mathrm{N}^{\circ} 1.094$, de 1975, ley de Extranjería, y establece normas para favorecer la integración de los migrantes y la migración segura. Diario Oficial de la República de Chile, Santiago, Chile, 23 de junio de 2016. Recuperado de https://www.camara.cl/pley/pley_detalle.aspx?prmID=11227

Boswell, C. (2008). Selling labour migration: democratic $v / s$ technocratic modes of justification. Italy: Centro Studi di Politica Internazionale CeSPI.

Brubaker, R. (2001). The return of assimilation? Changing perspectives on immigration and its sequels in France, Germany and the United States. Ethnic and Racial Studies, 24(4), 531-548.

Cámara de Diputados de Chile. (s. f.). Glosario. Chile: Autor. Recuperado de https://www.camara.cl/glosario.aspx

Cámara de Diputados de Chile. (2015). Acta de la sesión $72^{a}$, ordinaria, en martes 29 de septiembre de 2015, de 11:07 a 14:22 horas. Santiago, Chile: Autor. Recuperado de

https://www.camara.cl/pdf.aspx?prmid=11402\&prmtipo=TEXTOSESION

Castillo, I. (Coord.). (2011). Brechas de representación. Élites parlamentarias y ciudadanía en Chile. Chile: Observatorio Político Electoral ICSO/Universidad Diego Portales.

Castles, S. (2000). Ethnicity and Globalization. Londres: Sage. 
Castles, S. (2004). Why migration policies fail? Ethnic and Racial Studies, 27(2), 205-227.

Decreto Ley $\mathrm{n}^{\circ}$ 1094. Establece normas sobre extranjeros en Chile. Diario oficial de la República de Chile, Santiago, Chile, 19 de julio de 1975. Recuperado de https://www.leychile.cl/Navegar?idNorma $=6483$

Donoso Rojas, C. (2006). La idea de nación de 1810. Polis, (15), 1-28.

Doña Reveco, C. y Mullan, B. (2014). Migration Policy and Development in Chile. International Migration, 52(5), 1-15.

Doña Reveco, C. y Levinson, A. (2012). Chile: A growing Destination Country in Search of a Coherent Approach to Migration. United States: MPI.

Favel, A. (2014). Immigration, Integration and Mobility: New Agendas in Migration Studies. United Kingdom: European Consortium for Political Research Press.

Foro Bicentenario. (2008). Migración, Integración, Identidad. Miradas de Idas y de Vueltas. Sudamérica-Europa. Bicentenario. Chile: Comisión Bicentenario.

Gainza, P. (Coord.). (2013). Políticas migratorias e integración en América del Sur. Realidad del acceso a derechos político económicos, sociales y culturales de las personas migrantes. São Paulo, Brasil: Espacio sin Fronteras/CDHIC.

Gómez, L. (2003). ¿Chile, un Estado pluricultural, plurilingual? El desarrollo de las lenguas minoritarias en Chile. En J. Órdenes. (Coord.). (2003). El derecho a la lengua de los pueblos indígenas. XI Jornadas Lascanianas. México: UNAM. Recuperado de https://archivos.juridicas.unam.mx/www/bjv/libros/2/740/15.pdf

Gordon, M. (1964). Assimilation in American Life. Nueva York: Oxford University Press.

Hampshire, J. (2013). The Politics of Immigration: Contradictions of the Liberal State Cambridge: Polity Press.

Haynes, A., Power, M. J. y Devereux, E. (2016). Explaining EU migrant workers. Irish political interventions in public discourse. In A. Haynes, M. J. Power, J. Carr, E. Devereux y A. Dillane. (Eds.). Public and Political Discourses of Migration (pp. 187-215). London: International Rowman/Little Field International.

Hill, E. (2016). Welcoming nations? Hospitality as a proxy for national identity. A consideration of British and Scottish context. En A. Haynes, M. J. Power, J. Carr, E. Devereux y A. Dillane. (Eds.). Public and Political Discourses of Migration (pp. 339-361). London: International Rowman/Little Field International. 
Honohan, I. (2016). The acceptable face of assimilation? En A. Saeger. (Ed.). The ethics and politics of immigration. Core issues and emerging trents (pp. 250-274). London: Rowman \& Littlefield.

Instituto Nacional de Estadísticas. (2018a). Sintesis de Resultados Censo 2017. Chile: INE.

Instituto Nacional de Estadísticas. (2018b). Características de la inmigración internacional en Chile, Censo 2017. Chile: INE.

Instructivo Presidencial $n^{\circ}$ 9. Imparte instrucciones sobre la Política Nacional Migratoria. Diario Oficial de la República de Chile, Santiago, Chile, 2 de septiembre de 2008. Recuperado de https://transparenciaactiva.presidencia.cl/Otros\%20Antecedentes/16.\%20Inst. \%20N\%C2\%BA\%209.pdf

Instructivo Presidencial $\mathrm{n}^{\circ}$ 5. Lineamientos e instrucciones para la Política Nacional Migratoria. Diario Oficial de la República de Chile, Santiago, Chile, 6 de noviembre de 2015.2 Recuperado de https://transparenciaactiva.presidencia.cl/Otros\%20Antecedentes/Inst.\%20Pres.\%20 N\%C2\%BA5.pdf

Jiménez, T. (2011). Immigrants in the United States: How Well Are They Integrating into Society? Washington, D. C.: European University Institute/Robert Schuman Centre for Advances Studies/Migration Policy Institute.

Johnson, N. (2006). El desafío de la diferencia: la representación política de las mujeres y de los pueblos indígenas en Chile. En C. Fuentes y A. Villar. (Eds.). Desafios democráticos (p. 126). Santiago, Chile: Flacso Chile/LOM.

Joppke, C. (1999). Immigration and the Nation-State: The United States, Germany and Great Britain. United Kingdom: Oxford University Press.

Joppke, C. y Morawska, E. (2003). Integrating Immigrants in Liberal Nation-States: Policies and Practices. En Autores. (2003). Toward assimilation and citizenship: immigrants in Liberal Nation-States (pp. 1-36). United Kingdom: Palgrave Macmillan.

Larraín, J. (2010). Identidad chilena. Chile: LOM.

Machín, M. (2011). Los derechos humanos y la migración en Chile. Desafios y oportunidades para la convivencia intercultural. Temuco, Chile: Observatorio Ciudadano.

Mármora, L. (2002). Las políticas de migraciones internacionales. Buenos Aires, Argentina: Paidós/OIM. 
Martínez, J., Soffia, M., Cubides, J. D. y Bortolotto, I. (2013). Migración internacional en Chile: tendencias, políticas, normas y participación de la sociedad civil. En L. Chiarello. (Coord.). Las politicas públicas sobre migraciones y la sociedad civil en América Latina. Los casos de Bolivia, Chile, Paraguay y Perú (pp. 117-190). Nueva York: Scalabrini International Migration Network.

Navarrete, B. (2017). Percepciones sobre inmigración en Chile: lecciones para una política migratoria. Migraciones Internacionales, 9(1), 179-209.

Organisation for Economic Co-operation and Development. (2010). International Migration Outlook. Paris: SOPEMI/OECD.

Pairican, F. (2014). Malon: la rebelión del movimiento mapuche 1990-2013. Chile: Pehuén.

Portes, A. y Rumbaut, R. G. (1990). Immigrant America: A Portrait. Berkeley, CA: University of California Press.

Romero, C. (30 de noviembre de 2016). Irrupción de la inmigración en las presidenciales, populismo o contingencia. Emol. El Mercurio On Line. Recuperado de https://www.emol.com/noticias/Nacional/2016/11/30/833420/Irrupcion-de-lainmigracion-en-las-presidenciales-Populismo-o-contingencia.html

Rosenbluth, M., Littin, C., Farfán, C. y Rubio, M. J. (2012). Encuesta ser migrante en el Chile de hoy. Programa Comunicación y pobreza. Chile: Fundación Superación de la Pobreza/Escuela de la Comunicación Universidad Diego Portales.

Senado de Chile. (2015). Actas del Congreso, 15 diciembre 2015, sesión $81^{\circ}$ ordinaria, tabla. Santiago de Chile: Autor. Recuperado de: http://www.senado.cl/appsenado/index.php?mo=sesionessala\&ac=getDoctoSesion\&i ddocto $=57577$

Taylor, C. (1994). Politics of Recognition. En Charles Taylor \& Amy Gutmann. Multiculturalism: Examining the politics of recognition (pp. 25-73). United Kingdom: Princeton University Press.

Thayer Correa, L. E. (2013). Expectativas de reconocimiento y estrategias de incorporación: la construcción de estrategias degradadas en migrantes latinoamericanos residentes en la Región Metropolitana de Santiago. Polis, Revista Latinoamericana, 12(35), 259-285.

Torres, L. (2017). El escenario actual chileno y la inmigración internacional: legislación y postura de los partidos políticos. Migraciones Internacionales, 9(1), 269-277. 
22 Integration of Migrants in Chile. Multicultural Assimilation and Rhetoric

Torres Matus, L. R.

Usallán, L. (2015). El pluralismo cultural y la gestión política de la inmigración en Chile, ausencia de un modelo? Polis, Revista Latinoamericana, 14(42), 1-18.

Valenzuela, C. (2014). Rezago de la política migratoria en Chile: contención ante una demanda creciente. Búsquedas Políticas, 3(1), 27-54. 